\title{
System Analysis and Forecasting of the Relationship Between Economic Factors and the Epidemic Process COVID-19 to Optimize International Transport Communications in the Context of a Pandemic
}

\author{
Davidovsky A. \\ Belarusian State University of Informatics \& Radioelectronic, Minsk 220013, Belarus \\ "Corresponding author.Email: anatolydavidovsky2020@gmail.com; agd@bsuir.by
}

\begin{abstract}
Has been presents the results of system analysis and short-term forecasting of the impact of economic factors on the development of the epidemic process COVID-19 and assessment of opportunities of optimization of transport communications and logistics cooperation between countries with different socio-economic and demographic development, as well as geographical position in the global pandemic COVID-19. A kinetic model of the development of the epidemic process caused by the SARS-CoV-2 virus, represented by a system of linear differential equations, is developed. As a result of the study of this mathematical model, the conditions for stabilization and limitation of the epidemic process are obtained. Multiple linear regression models have been developed that characterize the dynamics of morbidity and survival of patients in the epidemic process, taking into account such economic indicators as the price of a barrel of Brent oil, one Troy ounce of gold and silver, bitcoin, the exchange rate of the Chinese yuan to the Russian ruble, the dollar to the Russian ruble, the Chinese yuan to the dollar. Conducted research for a number of countries, including Australia, Austria, Belarus, Germany, India, Spain, Italy, China, Latvia, Lithuania, Poland, Russia, USA, Ukraine, France, Estonia. A hypothesis is proposed about the incidence and survival gradients that may have a dynamically unstable equilibrium point in the context of the COVID-19 epidemic in a certain international cluster of countries (regions). The results of research and theoretical generalizations can be used to minimize social and economic losses in the face of repeated epidemics caused by COVID-19 and similar challenges in the future.
\end{abstract}

Keywords: COVID-19, epidemic process, system analysis, forecasting, mathematical simulation, linear

regression models, international transport logistics

\section{INTRODUCTION}

On March 11, 2020, the world health organization (who) announced that the spread of the new COVID-19 coronavirus (SARS-CoV-2) in the world has become a pandemic [1], which began with the discovery in late December 2019 in the city of Wuhan, Hubei province of Central China, the first cases of pneumonia of unknown origin in local residents associated with the local animal and seafood market. Starting from January 24, 2020, the virus was detected in all administrative divisions of China at the provincial level $[2,3]$. The post-crisis depression that engulfed developed countries after 2008-2009 crisis, as previously predicted, was prolonged and lasted until 20182020 , when a new increase in world production was expected due to the mass development and introduction of convergent technologies of the 6th Technological Order, the development of alternative sources of "clean energy» with a balanced and rational use of hydrocarbon energy resources - oil and gas [4]. The disruption of global logistics chains leads to a drop in global trade volumes and a slowdown in economic growth, provoking the sociotechnical crisis phenomena caused by the COVID-19 pandemic.

\subsection{The problem of the study}

Has been given the complex socio-demographic situation and the global aging of the population of Europe and North America, which suffers from all the «diseases of civilization», including cardiovascular, oncological and neurological diseases, it becomes obvious that prolonged quarantine measures of a global nature can be accompanied by difficult to predict socio-economic and socio-cultural consequences [5]. At the same time, it is particularly important to develop approaches, methods and tools for forecasting of COVID-19 pandemic while minimizing the negative social and socio-economic consequences, primarily short-term and operational with a forecast horizon from one week to six months. As such criteria may be 
offered such as the price of a barrel of Brent crude oil in U.S. dollars (USD), price per ounce of gold, the price for one Troy ounce of silver, bitcoin price (USD per 1 coin), the Chinese yuan and the Russian ruble, the US dollar to the Russian ruble and the Chinese yuan to the USD. This choice was due to the high dynamics of some criteria (the price of a barrel of Brent oil, the exchange rates of world currencies and cryptocurrencies in relation to each other), while the relative stability of others (a Troy ounce of gold and silver). In this regard, it should be noted that it is of considerable interest to study the impact of the above-mentioned economic indicators that characterize the state of the global economic system on such indicators of the COVID-19 epidemic process.

\subsection{The research goal}

The aim of this research - to systematically analyze and short - term forecast of the impact of economic factors on the spread of COVID-19 pandemic in some countries which are located in South-East and South Asia (India, China), high-tech countries characterized by progressive population aging and located in North America (USA), Western (Austria, Germany, Spain, Italy, France) and Eastern (Lithuania, Latvia, Poland, Estonia) Europe, as well as postsocialist countries with promising models of socioeconomic development (Belarus, Russia, Ukraine) and Australia.

\section{KINETIC SIMULATION OF THE COVID-19 PROCESS SPREAD}

\subsection{The COVID-19 infection spread is a typical epidemic process.}

As you know, any epidemic process is a continuous interaction between the pathogen - parasite and the human body at the species and population level on heterogeneous and evolutionarily related features. During the epidemic process, the relationship between the pathogen-parasite and the human body is expressed by both manifest and asymptomatic forms of infection that spread among the population over the territory, time, and risk groups for the development of the disease [6]. To simplify the task of describing and modeling the COVID-19 epidemic process in the human population, a kinetic approach was used. When modeling the development of the epidemic process, variables such as:

- the general population-G(t);

- individuals susceptible to infection (susceptible) - $\mathrm{S}(\mathrm{t})$;

- persons who are not susceptible to infection (non susceptible) - NS(t);

- persons who are in the acute stage of the disease (acute stage of the disease) - ASD $(\mathrm{t})$;

- persons who are in the chronic stage of the disease (chronic stage of the disease) - CSD $(t)$;
- recovering (convalescent $)-\mathrm{C}(\mathrm{t})$;

- recovered (recovered) - R(t);

- individuals that survive infection and received immunity, immune (immune) - I(t);

- persons who have completed the disease is fatal (fatal outcome of the disease) - FOD(t);

$-\mu(0-15)-$ constants or parameters that characterize the intensity of transitions between populations and subpopulations of individuals involved in the epidemic process.

\subsection{The kinetic model of the COVID-19 spread in the human population}

The kinetic model of the spread of COVID-19 infection in the human population may be described by a system of linear differential equations (1)-(8):

$\frac{d G}{d t}=\mu_{0}-\left(\mu_{1}+\mu_{2}\right) G$,

$\frac{d S}{d t}=\mu_{1} G+\mu_{9} I+\mu_{11} N S-\mu_{3} S$,

$\frac{d N S}{d t}=\mu_{2} G-\left(\mu_{10}+\mu_{11}\right) N S$,

$\frac{d A S D}{d t}=\mu_{3} S-\left(\mu_{4}+\mu_{5}+\mu_{12}\right) A S D$,

$\frac{d C S D}{d t}=\mu_{3} S+\mu_{4} A S D-\left(\mu_{6}+\mu_{13}\right) C S D$,

$\frac{d C}{d t}=\mu_{5} A S D+\mu_{7} C S D-\left(\mu_{8}+\mu_{14}\right) C$,

$\frac{d I}{d t}=\mu_{6} C-\left(\mu_{9}+\mu_{10}+\mu_{15}\right) I$,

$\frac{d F O D}{d t}=\mu_{12} A S D+\mu_{13} C S D+\mu_{14} C+\mu_{15} I$.

Applying the principle of quasi - stationarity to the system of differential equations (1)-(8) and equating the left part of each equation to zero, we can obtain a number of conditions for the stabilization of the infectious process $(9)-(16)$ :

$$
\begin{aligned}
& G=-\frac{\mu_{0}}{\left(\mu_{1}+\mu_{2}\right)}, \\
& S=\frac{\mu_{1} G+\mu_{9} I+\mu_{11} N S}{\mu_{3}}, \\
& N S=\frac{\mu_{2} G}{\left(\mu_{10}+\mu_{11}\right)}, \\
& A S D=\frac{\mu_{3} S}{\left(\mu_{4}+\mu_{5}+\mu_{12}\right)}, \\
& C S D=\frac{\mu_{3} S+\mu_{4} A S D}{\left(\mu_{6}+\mu_{13}\right)}, \\
& C=\frac{\mu_{5} A S D+\mu_{7} C S D}{\left(\mu_{8}+\mu_{14}\right)}, \\
& I=\frac{\mu_{6} C}{\left(\mu_{9}+\mu_{10}+\mu_{15}\right)}, \\
& \mu_{12} A S D+\mu_{13} C S D+\mu_{14} C+\mu_{15} I=0 .
\end{aligned}
$$


These expressions (10) - (16) can be useful for performing numerical experiments when studying the kinetics of the COVID-19 epidemic process based on the proposed mathematical model.

As the qualitative analysis of the proposed kinetic model shows, the total population exposed to COVID-19 should be constant, which implies that there are no migration flows that contribute to both an increase and a decrease in the total population $(\mathrm{G})$.

Moreover, the probability of finding a human population exposed to COVID-19 in a state of susceptibility to infection (S) depends on the biodemographic characteristics of the General (source) population $(\mathrm{G})$, including age structure, the presence of chronic diseases and the «genetic load» factor, as well as its relationship with subpopulations of recovering subjects (C), immune, i.e. resistant to the infectious agent (NS), as well as those who have been ill and acquired immunity, i.e. «immune» (I).

It should be noted that this model does not consider and does not take into account the probability of transition to a fatal outcome of the disease from the States of susceptibility (S) and lack of susceptibility (NS).

Special attention should be paid to the possibility of switching between immune and sensitive subpopulations $(\mathrm{I} \rightarrow \mathrm{S})$. This transition is due to the complete or partial loss of immunity of subjects who have suffered a coronavirus infection, with subsequent mutations of the SARS-CoV-2 virus.

Such mutations will be accompanied by changes in the pathogenesis and clinical picture of the development of the infectious process. At the same time, some representatives of the «immune» subpopulation may die, i.e. make the transition to the subpopulation of people with a fatal outcome of COVID-19 (I $\rightarrow$ FOD)

\subsection{The mathematical simulation of COVID-19 infection widespread}

The integration of the differential equation (1) allows us to obtain an expression for estimating the total population of subjects affected by COVID-19 (17):

$$
\begin{aligned}
& G(t)=G_{0} \exp \left[-\left(k_{1}+k_{2}\right) t+k_{0} \int_{0}^{+\infty} \frac{d t}{G_{(t \rightarrow 0)}}\right] \\
& (0 \leq G(t) \leq 1) .
\end{aligned}
$$

By adding equations (2) and (3), we obtain an expression for estimating the probability of susceptibility to COVID19 infection (18):

$$
\begin{aligned}
& S(t)=\frac{1}{\mu_{3}}\left[\frac{d s(t)}{d s}+\frac{d S N(t)}{d S}-\left(\mu_{1}+\mu_{2}\right) G(t)+\mu_{9} \operatorname{Im}(t)\right], \\
& (0 \leq S(t) \leq 1)
\end{aligned}
$$

By adding equations (4), (5) and (6), we obtain an expression for estimating the probability of the formation of a chronic stage of the infectious process (19):

$$
\begin{aligned}
& \operatorname{CSD}(t)=\frac{\frac{d A S D(t)}{d t}+\frac{d C S D(t)}{d t}+\frac{d C}{d t} \mu_{3} S+\left(\mu_{8}+\mu_{13}\right) C(t)}{\mu_{12}} \\
& (0 \leq \operatorname{CSD}(t) \leq 1) .
\end{aligned}
$$

From equation (7) we obtain an expression for estimating the probability of transition to the stage of recovery in the infectious process (20):

$C(t)=\frac{1}{\mu_{8}}\left(\frac{d \operatorname{Im}(t)}{d t}-\mu_{9} \operatorname{Im}(t)\right),(0 \leq C(t) \leq 1)$.

Using expressions (17) - (20) and the differential equation (8), we obtain an expression for quantifying the probability of a fatal outcome of the infectious process (21):

$$
\begin{aligned}
& F O D(t)=\left(\mu_{1}+\mu_{2}\right) \int_{0}^{+\infty} G(t) d t-N S(t)-S(t)+ \\
& +\mu_{8} \int_{0}^{+\infty} A S D(t)++A S D(t)+C S D(t)+ \\
& +C(t)-\operatorname{Im}(t)+K, \quad(0 \leq F O D(t) \leq 1)
\end{aligned}
$$

where $\mathrm{K}$ is the integration constant

In equation (21) are interconnected all the characteristics presented in the proposed mathematical model of the epidemic process represented by the differential equations (1) to (8) and expressions (9) - (21).

In addition, on the basis of the mathematical model (1) (21), we can distinguish at least three lines of development of epidemic process COVID-19, which can be described as transitions between different subpopulations of subjects exposed to the virus SARS-CoV-2:

a) $\mathrm{S} \rightarrow \mathrm{ASD} \rightarrow \mathrm{C} \rightarrow \mathrm{I} \rightarrow \mathrm{S}$;

b) $\mathrm{S} \rightarrow \mathrm{ASD} \rightarrow \mathrm{CSD} \rightarrow \mathrm{ASD} \rightarrow \mathrm{C} \rightarrow \mathrm{I} \rightarrow \mathrm{S}$;

c) $\mathrm{S} \rightarrow \mathrm{ASD} \rightarrow \mathrm{CSD} \rightarrow \mathrm{C} \rightarrow \mathrm{I} \rightarrow \mathrm{S}$.

The presence of such contours of the development of the epidemic process indicates the cyclical nature of its development due to the possibility of reinfection of the part of the human population that has already suffered infection and in which the formation of immunity (I) or chronization of the infectious process (CSD) could occur, as well as replenishment of the number of persons susceptible to infection (S). Thus, in order to minimize the risks of negative consequences of the COVID-19 epidemic process, it is advisable to consider it as a recurrent cyclical process.

\subsection{The short-term forecasting of regional dynamics of indicators of the COVID-19 epidemic process}

To solve the problem of short-term forecast of regional dynamics of indicators of the COVID-19 epidemic process, we used materials from international databases containing information on the number of cases, recovery and deaths. Data were collected and statistically processed on the daily dynamics of cases of illness, recovery and death from 31.12.2019 to 27.06.2020. MS Excel 2016 for Windows 10 was used to aggregate and statistically process data from 
who web resources (https://www.who.int/ru) and Johns Hopkins University (https://www.jhu.edu/). Later, based on statistically processed materials, characteristics were determined for a systematic analysis of the dynamics of the COVID-19 epidemic process. In particular, the «survival» index (the «morbidity-mortality» index - MMI) was proposed, calculated as the difference between the daily number of cases of morbidity and deaths per 1 million of the country's population (22):

$M M I=\frac{\text { cases of morbidity-cases of death }}{\text { day } \cdot[\text { million people population }]}$.

The influence of a number of important indicators that characterize the state of the world economy on the dynamics of the incidence of COVID-19 was studied. In particular, the impact of such indicators as the price of Brent crude oil, the price of Troy ounces of gold and silver (USD), the price of bitcoin the exchange rate of the yuan to the Russian ruble, the dollar to the Russian ruble and the yuan to the dollar. All collected statistical materials were examined for compliance with the normal distribution using the criteria of asymmetry and kurtosis. Mathematical linear regression models describing the impact of economic indicators on the dynamics of morbidity in Australia, Austria, Belarus, Germany, India, Spain, Italy, China, Latvia, Lithuania, Poland, Russia, USA, Ukraine, France and Estonia are obtained. A set of statistical data analysis methods, including exponential smoothing using the Holt-winters method for time series with seasonality, was used for shortterm forecasting of the dynamics of cases, recovery, and death [7].

\section{MATHEMATICAL SIMULATION AND SYSTEM ANALYSIS OF MORBIDITY AND SURVIVAL IN COVID-19 PANDEMIC}

For a system analysis of the daily dynamics of morbidity and survival of people with coronavirus infection, a set of mathematical models was developed based on the method of multiple linear regression of data from variation series of daily dynamics of morbidity, recovery and mortality indicators for 16 studied countries in the period from 31.12.2019 to 30.06.2020. It should be noted that all regression models were constructed in compliance with the requirements to prevent multicollinearity, heteroscedasticity, and autocorrelation of residuals [7, 8]. The daily increase in the incidence of COVID-19 in various countries [shown in square brackets] is represented by the following multiple linear regression equations $(23)-(38)$ :

[Australia] $=0,009 \mathrm{X}_{1}+2,25 \mathrm{E}-05 \mathrm{X}_{2}-0,004 \mathrm{X}_{3}-$

$-1,2 \mathrm{E}-05 \mathrm{X}_{4}+0,16 \mathrm{X}_{5}-0,013 \mathrm{X}_{6}-6,135 \mathrm{X}_{7}$

$\left(\mathrm{R}^{2}=0,992\right)$

where $X_{1}$ - the price of Brent crude (USD), $X_{2}$ - the price of one Troy ounce of gold (USD), $X_{3}$ - the price of one Troy ounce of silver (USD), $\mathrm{X}_{4}$ - bitcoin price (USD per 1 coin),
$\mathrm{X}_{5}$ - the Chinese yuan and the Russian ruble, $\mathrm{X}_{6}$ - the US dollar to the Russian ruble, $\mathrm{X}_{7}$-rate of the RMB against the U.S. dollar;

[Austria] $=0,008 \mathrm{X}_{1}+2,4 \mathrm{E}-05 \mathrm{X}_{2}-0,0046 \mathrm{X}_{3}-$ $-1,1 \mathrm{E}-05 \mathrm{X}_{4}+0,134 \mathrm{X}_{5}-0,011 \mathrm{X}_{6}-5,15 \mathrm{X}_{7}\left(\mathrm{R}^{2}=0,989\right)$;

[Belarus $]=-0,039 \mathrm{X}_{1}+0,0001 \mathrm{X}_{2}-0,001 \mathrm{X}_{3}+$ $+4,45 \mathrm{E}-05 \mathrm{X}_{4}-0,75 \mathrm{X}_{5}+0,065 \mathrm{X}_{6}+28,1 \mathrm{X}_{7}\left(\mathrm{R}^{2}=0,998\right)$;

$[$ Germany $]=-0,01 \mathrm{X}_{1}+3,13 \mathrm{E}-05 \mathrm{X}_{2}-0,001 \mathrm{X}_{3}+$ $+1,15 \mathrm{E}-05 \mathrm{X}_{4}-0,2 \mathrm{X}_{5}+0,017 \mathrm{X}_{6}+7,4772 \mathrm{X}_{7}\left(\mathrm{R}^{2}=0,998\right)$;

[India $]=0,012 \mathrm{X}_{1}+2,88 \mathrm{E}-05 \mathrm{X}_{2}-0,006 \mathrm{X}_{3}$ $-1,5 \mathrm{E}-05 \mathrm{X}_{4}+0,214 \mathrm{X}_{5}-0,02 \mathrm{X}_{6}-8,13 \mathrm{X}_{7}\left(\mathrm{R}^{2}=0,994\right)$;

[Spain $]=3,64 \mathrm{E}-05 \mathrm{X}_{2}-0,004 \mathrm{X}_{3}-1,5 \mathrm{E}-06 \mathrm{X}_{4}-$ $-0,02 \mathrm{X}_{5}+0,003 \mathrm{X}_{6}+0,64 \mathrm{X}_{7}\left(\mathrm{R}^{2}=0,999\right)$;

[Italy $]=0,005 \mathrm{X}_{1}+2,89 \mathrm{E}-05 \mathrm{X}_{2}-0,004 \mathrm{X}_{3}$

$-7,7 \mathrm{E}-06 \mathrm{X}_{4}+0,081 \mathrm{X}_{5}-0,006 \mathrm{X}_{6}-3,15 \mathrm{X}_{7}\left(\mathrm{R}^{2}=0,965\right)$;

[China $]=0,003 \mathrm{X}_{1}-0,001 \mathrm{X}_{2}+0,052 \mathrm{X}_{3}+$ $+3,52 \mathrm{E}-05 \mathrm{X}_{4}+0,225 \mathrm{X}_{5}-0,027 \mathrm{X}_{6}-4,3 \mathrm{X}_{7}\left(\mathrm{R}^{2}=0,971\right)$;

[Latvia] $=-0,0216 \mathrm{X}_{1}+7,58 \mathrm{E}-05 \mathrm{X}_{2}-0,003 \mathrm{X}_{3}+$ $+2,41 \mathrm{E}-05 \mathrm{X}_{4}-0,42 \mathrm{X}_{5}+0,037 \mathrm{X}_{6}+15,73 \mathrm{X}_{7}\left(\mathrm{R}^{2}=0,998\right)$;

[Lithuania] $=-0,013 \mathrm{X}_{1}+6,15 \mathrm{E}-05 \mathrm{X}_{2}-0,0032 \mathrm{X}_{3}+$ $+1,37 \mathrm{E}-05 \mathrm{X}_{4}-0,26 \mathrm{X}_{5}+0,023 \mathrm{X}_{6}+9,5 \mathrm{X}_{7}\left(\mathrm{R}^{2}=0,998\right)$;

$[$ Poland $]=-0,025 \mathrm{X}_{1}+7,97 \mathrm{E}-05 \mathrm{X}_{2}-0,0022 \mathrm{X}_{3}+$ $+2,8 \mathrm{E}-05 \mathrm{X}_{4}-0,485 \mathrm{X}_{5}+0,042 \mathrm{X}_{6}+18,14 \mathrm{X}_{7}\left(\mathrm{R}^{2}=0,998\right)$;

[Russia] $=-0,029 \mathrm{X}_{1}+9,05 \mathrm{E}-05 \mathrm{X}_{2}-0,002 \mathrm{X}_{3}+$ $+3,28 \mathrm{E}-05 \mathrm{X}_{4}-0,55 \mathrm{X}_{5}+0,048 \mathrm{X}_{6}+20,77 \mathrm{X}_{7}\left(\mathrm{R}^{2}=0,998\right)$;

[USA $]=-0,008 \mathrm{X}_{1}+5,07 \mathrm{E}-05 \mathrm{X}_{2}-0,00337 \mathrm{X}_{3}+$ $+7,91 \mathrm{E}-06 \mathrm{X}_{4}-0,167 \mathrm{X}_{5}+0,015 \mathrm{X}_{6}+6,183 \mathrm{X}_{7}\left(\mathrm{R}^{2}=0,999\right)$;

[Ukraine] $=-0,047 \mathrm{X}_{1}+0,000115 \mathrm{X}_{2}-0,00052 \mathrm{X}_{3}+$ $+5,35 \mathrm{E}-05 \mathrm{X}_{4}-0,89 \mathrm{X}_{5}+0,076 \mathrm{X}_{6}+33,37 \mathrm{X}_{7}\left(\mathrm{R}^{2}=0,998\right)$;

$[$ France $]=0,0015 \mathrm{X}_{1}+3,7 \mathrm{E}-05 \mathrm{X}_{2}-0,004 \mathrm{X}_{3}-3,2 \mathrm{E}-06 \mathrm{X}_{4}+$

$+0,0124 \mathrm{X}_{5}-0,00015 \mathrm{X}_{6}-0,56 \mathrm{X}_{7}\left(\mathrm{R}^{2}=0,998\right)$;

[Estonia $]=0,003 \mathrm{X}_{1}+3,23 \mathrm{E}-05 \mathrm{X}_{2}-0,00423 \mathrm{X}_{3}-$ $-5,4 \mathrm{E}-06 \mathrm{X}_{4}+0,045 \mathrm{X}_{5}-0,003 \mathrm{X}_{6}-1,78 \mathrm{X}_{7}\left(\mathrm{R}^{2}=0,958\right)$.

In addition, the multiple linear regression models were constructed for the impact of economic factors on the dynamics of survival in various countries in the context of the COVID-19 pandemic (39) - (54):

[Australia] $=0,090 \mathrm{X}_{1}+0,001 \mathrm{X}_{2}-0,079 \mathrm{X}_{3}+$

$+1,305 \mathrm{X}_{5}-0,087 \mathrm{X}_{6}-53,158 \mathrm{X}_{7} \quad\left(\mathrm{R}^{2}=0,923\right)$;

[Austria $]=0,008 \mathrm{X}_{1}-0,005 \mathrm{X}_{3}+0,134 \mathrm{X}_{5}-$

$-0,010 \mathrm{X}_{6}-5,151 \mathrm{X}_{7} \quad\left(\mathrm{R}^{2}=0,99\right)$; 
[Belarus $]=-0,001 \mathrm{X}_{1}-0,016 \mathrm{X}_{5}+0,001 \mathrm{X}_{6}+0,604 \mathrm{X}_{7}$ $\left(\mathrm{R}^{2}=0,998\right)$;

[Germany $]=0,003 \mathrm{X}_{1}-0,004 \mathrm{X}_{3}+0,034 \mathrm{X}_{5}-$ $-0,002 \mathrm{X}_{6}-1,384 \mathrm{X}_{7}\left(\mathrm{R}^{2}=0,984\right)$;

[India $]=0,012 \mathrm{X}_{1}-0,006 \mathrm{X}_{3}+0,214 \mathrm{X}_{5}-$

$-0,017 \mathrm{X}_{6}-8,125 \mathrm{X}_{7}\left(\mathrm{R}^{2}=0,994\right)$;

$[$ Spain $]=3,822 \mathrm{X}_{1}+0,006 \mathrm{X}_{2}-1,606 \mathrm{X}_{3}-0,005 \mathrm{X}_{4}+$ $+67,039 \mathrm{X}_{5}-5,409 \mathrm{X}_{6}-2555,942 \mathrm{X}_{7}\left(\mathrm{R}^{2}=0,994\right)$;

[Italy $]=0,002 \mathrm{X}_{1}-0,013 \mathrm{X}_{3}-0,011 \mathrm{X}_{5}+$

$+0,004 \mathrm{X}_{6}+0,114 \mathrm{X}_{7}\left(\mathrm{R}^{2}=0,999\right)$;

[China $]=0,001 \mathrm{X}_{3}+0,006 \mathrm{X}_{5}-0,001 \mathrm{X}_{6}-0,161 \mathrm{X}_{7}$ $\left(\mathrm{R}^{2}=0,997\right)$;

[Latvia $]=-62,28 \mathrm{X}_{1}+0,14 \mathrm{X}_{2}+0,8 \mathrm{X}_{3}+0,07 \mathrm{X}_{4}-$ $\left.-1181,9 \mathrm{X}_{5}+101,2 \mathrm{X}_{6}+44426,6 \mathrm{X}_{7} \mathrm{R}^{2}=0,998\right)$;

[Lithuania] $=-19,6 \mathrm{X}_{1}+0,06 \mathrm{X}_{2}+1,7 \mathrm{X}_{3}-0,02 \mathrm{X}_{4}+$

$+379,4 \mathrm{X}_{5}+32,895 \mathrm{X}_{6}+14216,3 \mathrm{X}_{7}\left(\mathrm{R}^{2}=0,998\right)$;

[Poland $]=1,28 \mathrm{X}_{1}-0,001 \mathrm{X}_{2}-0,171 \mathrm{X}_{3}-0,002 \mathrm{X}_{4}+$ $+23,875 \mathrm{X}_{5}-2,017 \mathrm{X}_{6}-901,1 \mathrm{X}_{7}\left(\mathrm{R}^{2}=0,997\right)$;

[Russia $]=-0,033 \mathrm{X}_{1}+0,000 \mathrm{X}_{2}+0,001 \mathrm{X}_{3}+$ $+0,000 \mathrm{X}_{4}-0,620 \mathrm{X}_{5}+0,053 \mathrm{X}_{6}+23,318 \mathrm{X}_{7}\left(\mathrm{R}^{2}=0,998\right)$;

[USA] $=2,086 \mathrm{X}_{1}+0,004 \mathrm{X}_{2}-0,9 \mathrm{X}_{3}-0,003 \mathrm{X}_{4}+$

$+36,8 \mathrm{X}_{5}-2,97 \mathrm{X}_{6}-1402,5 \mathrm{X}_{7}\left(\mathrm{R}^{2}=0,994\right)$;

[Ukraine $]=0,140 \mathrm{X}_{1}-0,071 \mathrm{X}_{3}+2,514 \mathrm{X}_{5}-$

$-0,205 \mathrm{X}_{6}-96,2 \mathrm{X}_{7} \quad\left(\mathrm{R}^{2}=0,994\right)$;

[France $]=1,5 \mathrm{X}_{1}+0,003 \mathrm{X}_{2}-0,633 \mathrm{X}_{3}-0,002 \mathrm{X}_{4}+$

$+26,2 \mathrm{X}_{5}-2,1 \mathrm{X}_{6}-996,9 \mathrm{X}_{7} \quad\left(\mathrm{R}^{2}=0,994\right)$;

[Estonia] $=1,16 \mathrm{X}_{1}+0,002 \mathrm{X}_{2}-0,49 \mathrm{X}_{2}-0,002 \mathrm{X}_{4}+$

$+20,4 \mathrm{X}_{5}-1,6 \mathrm{X}_{6}-776,4 \mathrm{X}_{7} \quad\left(\mathrm{R}^{2}=0,994\right)$.

Short-term forecasting for the period from 01.07.2020 to 31.12.2020 on the indicators of cases, recovery and death, as well as the survival rate using the is indicator was carried out for 16 countries, such as Australia, Austria, Belarus, China, Estonia, France, Germany, India, Italy, Latvia, Lithuania, Poland, Russia, the United States, Ukraine.

As follows from the analysis of the dynamics of the proposed is parameter as a survival indicator, in countries with a complex course of the COVID-19 epidemic process, the predicted values of the short-term forecast horizon (July-December 2020) go into the region of negative values. This indicates the probability of a pessimistic scenario for the development of the epidemic process and an increasing threat to the health and life of the population affected by the SARS-CoV-2 virus factor. Based on the results of mathematical modeling and system analysis of the obtained models, these countries can include the United States, Italy,
Poland, and Russia. At the same time, it should be noted that active measures to combat the COVID-19 epidemic process, especially the rational organization of passenger and commodity transport flows, can prevent the risk of infection and minimize the likelihood of a negative scenario in these countries.

However, the assessment of the dynamics of the epidemic in China, Germany, Belarus and Ukraine suggests a significant probability of an optimistic scenario for the development of the epidemic process and its favorable end during the summer season. The reasons for this can be both the effective organization of anti-epidemic measures, and the behavior of a significant part of the population. During the epidemic process, the movement of people and equipment is carried out in accordance with the principle of «three zones and two transitions»: infected zone, potentially infected zone and clean zone. The limits of these three zones are clearly marked, with the infected and potentially infected zones separated by buffer zones [9].

\section{THE IMPACT OF THE ECONOMIC INDICATORS ON COVID-19 MORBIDITY}

Projected daily increase in the incidence (cases per 1 million population) in January-June 2020 is characterized by a gradient increasing in a number of countries, including India, Australia, Austria, Italy, China, Estonia, France, Spain, USA, Germany, Lithuania, Latvia, Poland, Russia, Belarus and Ukraine.

The growing influence of such an economic factor as the price of Brent crude oil (in USD) can be traced in a number of countries, such as Ukraine, Belarus, Russia, Poland, Latvia, Lithuania, Germany, the United States, Spain, France, China, Estonia, Italy, Austria, Australia, India.

The impact of such economic factors as the price of an ounce of gold (USD), epidemic COVID-19 increases in the number of countries, including China, Australia, Austria, India, Italy, Germany, Estonia, Spain, France, USA, Lithuania, Latvia, Poland, Russia, Belarus and Ukraine.

The impact of such economic factors as the price of an ounce of silver (USD) in the epidemic increases in the number of countries, such as India, Austria, Italy, Estonia, France, Australia, Spain, USA, Lithuania, Latvia, Poland, Russia, Belarus, Germany, Ukraine and China.

The impact of such economic factors, such as bitcoin (USD per 1 bitcoin), the epidemic gradually increases in a number of countries, starting with India and beyond including Australia, Austria, Italy, Estonia, France, Spain, USA, Germany, Lithuania, Latvia, Poland, Russia, China, Belarus, Ukraine.

The yuan exchange rate against the Russian ruble is having a growing impact on the epidemic in a row, including Ukraine, Belarus, Russia, Poland, Latvia, Lithuania, Germany, USA, Spain, France, Estonia, Italy, Austria, Australia, India and China.

The dollar's exchange rate against the Russian ruble appears to be increasing its impact on the COVID-19 epidemic in countries such as China, India, Australia, Austria, Italy, 
Estonia, France, Spain, the United States, Germany, Lithuania, Latvia, Poland, Russia, Belarus, and Ukraine. In addition, the exchange rate of the Chinese yuan to the US dollar seems to have a consistently increasing impact on the development of the COVID-19 epidemic process in countries such as India, Australia, Austria, China, Italy, Estonia, France, Spain, the United States, Germany, Lithuania, Latvia, Poland, Russia, Belarus, and Ukraine. As follows from the results of the statistical analysis of data on the daily increase in incidence, recovery and mortality rate of the epidemic COVID-19 in the countries studied, the survival rate (SFL) gradually increases, moving to the positive values in several countries, consistently including Spain, USA, Poland, France, Estonia, Ukraine, Australia, India, Austria, China, Germany, Belarus, Italy, Russia, Lithuania and Latvia. This sequence allows us to make a reasonable assumption about the possibility of transition of certain countries to a favorable stage of development of the epidemic process in comparison with others in the same international cluster. In this case, from a formal point of view and under favorable conditions, Latvia, Lithuania and Russia form the top three, while Spain, the United States, and Poland form the bottom three.

The price of Brent crude oil (USD) may have an increasing impact on the daily increase in survival and, as a result, an increase in the ISI indicator in the positive range of values in the COVID-19 epidemic process in countries such as Latvia, Lithuania, Russia, Belarus, China, Italy, Germany, Austria, India, Australia, Ukraine, Estonia, Poland, France, the United States and Spain.

The price of one Troy ounce of gold (USD) increases the impact on the daily increase in COVID-19 survival in countries such as Poland, China, Belarus, Austria, India, Germany, Russia, Italy, Ukraine, Australia, Estonia, France, the United States, Spain, Lithuania and Latvia.

The price of one Troy ounce of silver (USD) consistently increases the impact on daily survival gains in countries such as Lithuania, Spain, USA, France, Estonia, Poland, Australia, Ukraine, Italy, India, Austria, Germany, Belarus, Russia, China and Latvia.

Bitcoin price (USD per 1 coin) enhances the effect on the survival rate in a number of countries, including Spain, USA, France, Poland, Estonia, Ukraine, Australia, India, Austria, Italy, Germany, China, Belarus, Russia, Lithuania and Latvia.

At the same time, the exchange rate of the yuan to the Russian ruble increases its impact on the survival rate of COVID-19 in countries such as Latvia, Lithuania, Russia, Belarus, Italy, China, Germany, Austria, India, Australia, Ukraine, Estonia, Poland, France, the United States and Spain.

The dollar exchange rate against the Russian ruble and the Chinese yuan may consistently reinforce a stimulating effect on the continuation of the epidemic process COVID19 in countries such as Spain, USA, France, Poland, Estonia, Ukraine, Australia, India, Austria, China, Germany, Belarus, Italy, Russia, Lithuania and Latvia. Based on these results of the analysis of the impact of economic indicators on the morbidity and survival of patients in the COVID-19 epidemic process, the hypothesis of «gradients of daily increase in morbidity and survival» in the human population is proposed and justified.

\section{CONCLUSION}

Has been shown, that all the studied economic factors have a significant, although ambiguous, impact on the dynamics of daily increase in morbidity and survival in the COVID19 epidemic in the studied countries of the world. The influence of the studied economic factors has a significant geographical and regional specificity. For example, the same economic factors show the opposite effect on the parameters of the COVID-19 epidemic process in countries of southern, Western and Eastern Europe, as well as in Australia, the United States, Belarus, Russia and Ukraine. At the same time, attention is drawn to a certain similarity in the effects of economic factors on the dynamics of indicators of the COVID-19 epidemic process in postsocialist countries.

According to N. Taleb, who introduced the concept of «black Swan» in his bestseller of the same name [10], «we do not yet have reliable statistics on how the virus behaves». Given a relatively long period of quarantine measures and social isolation for one to three years, the transition to widespread implementation of cyber-physical systems of various scales and purposes, including «smart home», «smart enterprise», «smart road», «smart city», and «smart region» can be significantly accelerated. The online communication and online education based on the Internet social network platforms will be in high demand. The traditional educational system will undergo significant transformation that will exceed any and all expectations and assumptions of today.

Thus, the research results obtained may be used for shortterm forecasting of the dynamics of the COVID-19 epidemic process in the studied countries under conditions of socio-economic turbulence. Timely short-term forecasting of possible spikes in the daily dynamics of morbidity against the background of negative trends in the survival rate of patients will allow for the preventive redistribution of medical, food, energy resources, as well as highly qualified personnel of various professional categories within the framework of international and crossborder cooperation in the context of the COVID-19 pandemic.

\section{REFERENCES}

[1] C. Huang, Y. Wang, X. Li, L. Ren, J. Zhao, Y. Hu, et al. Clinical features of patients infected with 2019 novel coronavirus in Wuhan, China, Lancet. Vol. 395 (2020) pp. 497-506.

[2] Y. Yang, F. Peng, R. Wang, K. Guan, T. Jiang, G. $\mathrm{Xu}$, J. Sun, C. Chang. The deadly coronaviruses: The 2003 SARS pandemic and the 2020 novel coronavirus epidemic in China, J. Autoimmun. Vol. 109 (2020), pp. 1-10. DOI: 10.1016/j.jaut.2020.102434 
[3] Y. Singh Malik, S. Sircar, S. Bhat, K. Sharun, K. Dhama, M. Dadar, R. Tiwari, W. Chaicumpa. Emerging novel coronavirus (2019-nCoV)-current scenario, evolutionary perspective based on genome analysis and recent developments, Vet. Q., 40(1) (2020), pp. 6876. DOI: $10.1080 / 01652176.2020 .1727993$.

[4] A. Akaev, A. Korotaev. To forecasting the global economic dynamics of the next few years, Economic policy, Vol. 12, N1 (2017) pp. 8-39.

[5] A. Akaev. Year of bifurcation in the dynamics of the world economy, Bulletin of the Russian Academy of Sciences, Vol. 85, N12 (2015) pp. 1-11.

[6] L. Zueva, R. Yafaev. Epidemiology: textbook. SPb., 2005.

[7] P. Newbold, W.L. Carlson, B.M. Thorne. Statistics for Business and Economics (8-th edition). Pearson Education, 2013.

[8] J. Foreman. Many numbers: big data analysis using Excel (2nd ed). M.: Alpina Publisher, 2019.

[9] T. Khan. Preventive and Control Measures of COVID-19 Patients: A Review, Bangladesh Journal of Infectious Diseases, Vol. 7, Suppl. 1 (2020), pp. S41S44. DOI: https://doi.org/10.3329/bjid.v7i0.46800.

[10] N. Taleb. Black Swan. Under the sign of unpredictability (2nd ed.). M.: Kolibri, Azbuka-Atticus, 2014. 